\title{
Confirmation of botulism in birds and cattle by the mouse bioassay and Endopep-MS
}

\author{
Mikael Hedeland, ${ }^{1,2}$ Hercules Moura, ${ }^{3}$ Viveca Båverud, ${ }^{4}$ \\ Adrian R. Woolfitt, ${ }^{3}$ UIf Bondesson ${ }^{1,2}$ and John R. Barr ${ }^{3}$ \\ ${ }^{1}$ National Veterinary Institute (SVA), Department of Chemistry, Environment and Feed Hygiene, \\ SE-751 89 Uppsala, Sweden \\ ${ }^{2}$ Uppsala University, Division of Analytical Pharmaceutical Chemistry, Biomedical Centre, \\ PO Box 574, SE-751 23 Uppsala, Sweden \\ ${ }^{3}$ Centers for Disease Control and Prevention, NCEH/DLS, 4770 Buford Hwy NE, Atlanta, \\ GA 30341-3724, USA \\ ${ }^{4}$ National Veterinary Institute (SVA), Department of Bacteriology, SE-751 89 Uppsala, Sweden
}

Correspondence

Mikael Hedeland

mikael.hedeland@sva.se

Received 13 February 2011

Accepted 5 May 2011
There have been several outbreaks of botulism among poultry and wild birds in Sweden in recent years. The National Veterinary Institute of Sweden (SVA) has identified botulinum neurotoxin (BoNT)/C1 or the mosaic BoNT/C1D using the mouse bioassay. This is believed to be the first report on the application of the Endopep mass spectrometry (Endopep-MS) method to selected clinical animal (serum and liver) samples and a feed sample that had previously given positive test results with the mouse bioassay. In the mouse bioassay eight of the eleven samples were found to be neutralized by both BoNT/C1 and /D antitoxins; the other three were neutralized only by BoNT/C1 antitoxin, but the mice showed a prolonged survival time when the samples had been treated with /D antitoxin. The Endopep-MS analysis, on the other hand, demonstrated only BoNT/C1 activity for all eleven samples. This suggests that at least eight of the samples were of the chimeric toxin type BoNT/C1D, where the enzymically active site is identical to that of BoNT/C1, while other parts of the protein contain sequences of BoNT/D. This is the first step of a cross-validation between the established mouse bioassay and the Endopep-MS of serotypes BoNT/C1 and /C1D. Endopep-MS is concluded to have potential as an attractive alternative to the mouse bioassay.

\section{INTRODUCTION}

Botulinum neurotoxins (BoNTs) are the most potent toxins known (Schiavo et al., 2000). They are produced under anaerobic conditions by some species of the genus Clostridium, particularly C. botulinum, C. butyricum, C. baratii and $C$. argentinense. BoNTs cause the disease botulism, which is manifested by flaccid paralysis (Johnson \& Montecucco, 2008). This is a severe condition that may be fatal without proper treatment and aggressive supportive care (Schiavo et al., 2000). There are at least seven serotypes of BoNT, which are denoted with the letters A to G. Human illness is usually caused by the types /A, /B, /E and /F, whereas /C and /D have been shown to affect mainly animals. Botulism can be acquired through the ingestion of food containing the toxin, or colonization

Abbreviations: BoNT, botulinum neurotoxin; MALDI, matrix-assisted laser desorption ionization.

Supplementary figures showing mass spectra from all the samples analysed are available with the online version of this paper. of the bacteria in either the gastrointestinal tract or a wound (Quinn et al., 1994).

The BoNTs are proteins of about $150 \mathrm{kDa}$, consisting of one light chain of $50 \mathrm{kDa}$ and one heavy chain of $100 \mathrm{kDa}$, linked together by a disulfide bridge (Wictome \& Shone, 1998). The toxin is released from the bacteria as a noncovalent complex with other, non-toxic proteins. The nontoxic associated proteins are thought to enable systemic exposure of the toxin by promoting its absorption through the intestinal mucosal epithelium (Fujinaga et al., 1997). However, animal experiments have demonstrated that pure BoNT/A can survive passage through the stomach and can be absorbed, although to a lower extent (Maksymowych et al., 1999). The BoNTs are zinc-dependent proteases and their mechanism of action is based on cleavage of different proteins in the SNARE complex which are involved in acetylcholine release from motor neurons (Schiavo et al., 2000). BoNT/A, /C1 and /E cleave at different sites of SNAP-25, and BoNT/B, /D, /G and /F are selective for VAMP-2. BoNT/C1 also has syntaxin A1 as an additional 
target. The light protein chain contains the enzymically active site, while the heavy chain is responsible for the binding and transport into the neuron. The unique target proteins and cleavage sites have been characterized for all seven toxin types (Johnson \& Montecucco, 2008).

In the past 10 years, there have been many cases of botulism among both wild and farm animals. One large outbreak caused by BoNT/C1 occurred in Finland in 2002 among fur production animals such as foxes and mink (Lindström et al., 2004). In Korea, at least five outbreaks have been described affecting wild birds in the period 2004-2008 (Shin et al., 2010). Botulism has also afflicted the Swedish poultry population during this same time period. The first case was reported in 2003 , and during 2008 outbreaks were confirmed in 13 different broiler farms (Blomqvist et al., 2009; Skarin et al., 2010). Furthermore, botulism was also reported in seabirds, primarily herring gulls, in the south-eastern part of Sweden in 2000-2004 (Neimanis et al., 2007).

A real-time PCR assay was developed for the BoNT/C1 gene as an alternative to the mouse bioassay for detection and identification of C. botulinum serotype /C (Lindberg et al., 2010). Interestingly, sequencing of the amplicons obtained from caecum samples from Swedish outbreaks gave data consistent with a chimeric /C1D sequence, earlier described in Japan (Takeda et al., 2005).

It is required that the presence of toxin is demonstrated in serum of a suspected animal for confirmation of botulism (Quinn et al., 1994). The reference method for the detection and identification of the active toxin is still the mouse bioassay, where mice are injected with the sample or an extract of the sample (Quinn et al., 1994; Kautter \& Solomon, 1977). The mouse bioassay is a time-consuming and expensive method requiring use of laboratory animals. The development of a comparable alternative analytical method for this purpose has not been straightforward, owing to the chemical nature of the BoNTs in combination with their extreme toxicity. Very high detection sensitivity and specificity, and the ability to exclusively measure the active toxin, are thus requirements for a new method to complement the mouse bioassay. A few alternative approaches have been described, such as activity-based methods using synthetic substrate peptides and ELISA detection of cleavage products (Evans et al., 2004; Hallis et al., 1996; Wictome et al., 1999a, b). A peptidase activity method selective for BoNT/C1 with immunological detection has also been presented (Jones et al., 2009). Furthermore, Evans et al. (2009) presented a new concept in which synaptosomes from rat brain were used for in vitro capture and activity measurement of BoNTs. Recently, a method for the detection of BoNT/B activity in foodstuffs and human serum using antibodies coupled to microchips was presented (Ferracci et al., 2011).

In 2005, another concept was reported, based on BoNT cleavage of synthetic peptides followed by detection of the product peptides by matrix-assisted laser desorption ionization (MALDI) and/or electrospray ionization (ESI) mass spectrometry (MS) (Barr et al., 2005; Boyer et al., 2005). The method, denoted Endopep-MS, was proven to be successful for detection of all seven BoNT serotypes in buffer solution, and the detection limits for BoNT/A, /B, /E and $/ F$ were lower than those obtained by the mouse bioassay. Further development of the Endopep-MS method, including an immunoaffinity purification step, enabled detection of BoNT/A, /B, /E and /F in human sera and stool samples (Kalb et al., 2006). The Endopep-MS method has also been applied for the detection of BoNT/A in spiked milk samples (Kalb et al., 2005). Recently, a paper on optimization of reaction conditions for BoNT/C1 and /DC1 in buffer solution was published (Moura et al., 2011).

In the present study, selected clinical samples (serum and liver) and one feed sample, all of which tested positive for BoNT/C1 or /C1D using the mouse bioassay, were analysed by Endopep-MS. The purpose was for the first time to apply the Endopep-MS method to real samples of animal origin and thereby to take the initial step towards a crossvalidation with the mouse bioassay.

\section{METHODS}

Materials. BoNT/A, /B, /C, /D, /E and /F complexes were obtained from Metabiologics and were provided at $1 \mathrm{mg}$ total protein $\mathrm{ml}^{-1}$ in $50 \mathrm{mM}$ sodium citrate buffer, $\mathrm{pH}$ 5.5. The toxin activities in mouse $\mathrm{LD}_{50}$ (the dose which kills $50 \%$ of the mice) per mg protein obtained from the supplier were $3.6 \times 10^{7} \mathrm{BoNT} / \mathrm{A}, 1.6 \times 10^{7} \mathrm{BoNT} / \mathrm{B}, 4.6 \times 10^{6}$ $\mathrm{BoNT} / \mathrm{C} 1,2.4 \times 10^{7} \mathrm{BoNT} / \mathrm{D}, 2.8 \times 10^{7} \mathrm{BoNT} / \mathrm{E}$ and $5.5 \times 10^{7} \mathrm{BoNT} /$ F. Because BoNT is very toxic and requires appropriate safety measures all neurotoxins were handled within a class 2 biosafety cabinet equipped with HEPA filters. The antitype-specific BoNT polyclonal rabbit IgGs were supplied by Metabiologics in $150 \mathrm{mM}$ potassium phosphate ( $\mathrm{pH} 7.4)$ at the supplier-indicated levels: anti/A at $4.61 \mathrm{mg} \mathrm{ml}^{-1}$, anti-/B at $5.46 \mathrm{mg} \mathrm{ml}^{-1}$, anti-/E at $8.26 \mathrm{mg} \mathrm{ml}^{-1}$ and anti-/F at $7.35 \mathrm{mg} \mathrm{ml}^{-1}$. Custom-made peptide-based affinitypurified IgGs against specific linear sequences of BoNT/C1, /C1D, /D and /DC1 were obtained from GenScript. These IgGs have been used in a previous study (Moura et al., 2008). Peptides were synthesized by Los Alamos National Laboratory, and the sequences of the substrates and the cleavage products were the same as the ones described by Boyer et al. (2005), with the addition of peptides 128 and 171 (see Table 1) for increased certainty in the detection of BoNT/C1. Dynabeads Protein $\mathrm{G}$ were purchased from Invitrogen at $1.3 \mathrm{~g} \mathrm{ml}^{-1}$ in PBS (pH 7.4) containing $0.1 \%$ Tween 20 (PBST) and $0.02 \%$ sodium azide. All other chemicals were from Sigma-Aldrich except where indicated otherwise.

For the mouse bioassay, antitoxins to BoNT/A, /B, /D and $/ \mathrm{E}$ (National Institute for Biological Standards and Controls, UK) and to BoNT/C1 (developed from C. botulinum strain Stockholm by the Department of Bacteriology, National Veterinary Institute, Uppsala, Sweden) were used.

Samples. Blood was collected fresh in sterile tubes without anticoagulant from euthanized chickens having clinical signs of botulism. Samples from 10 animals per farm were centrifuged and pooled into one sample to obtain sufficient material to test by the mouse bioassay. The pelleted poultry feed sample was taken from the 'feeding machine' near a dead bird in a flock with a confirmed outbreak of botulism. Liver samples (20 g) were taken from two 
Table 1. Peptide substrates and cleavage products for BoNT/C1 and /D

\begin{tabular}{|c|c|c|c|}
\hline \multirow[t]{4}{*}{4} & BoNT/C1 substrate & Biotin-KGSNRTRIDEANQRATRMLGGK-biotin & 2911.5 \\
\hline & BoNT/C1 NT product & Biotin-KGSNRTRIDEANQR & 1870.9 \\
\hline & BoNT/C1 internal standard & Biotin-KGSNRTRIDE $(A+7 *) \mathrm{N} Q R$ & 1877.9 \\
\hline & BoNT/C1 internal standard & $(A+7 *)$ TRMLGGK-biotin & 1066.5 \\
\hline \multirow[t]{2}{*}{128} & BoNT/C1 substrate & YVERAVSDSKKAVKYQSKARRKK-perfluoro $\dagger$ & 3099.5 \\
\hline & BoNT/C1 CT product & AVKYQSKARRKK-perfluoro $\dagger$ & 1836.9 \\
\hline \multirow[t]{3}{*}{171} & BoNT/C1 substrate & Biotin-KGSNRTRIDEANQRATRMLGGK-PEG-amineł & 3151.6 \\
\hline & BoNT/C1 NT product & Biotin-KGSNRTRIDEANQR & 1870.9 \\
\hline & BoNT/C1 CT product & ATRMLGGK-PEG-amine & 1299.8 \\
\hline \multirow[t]{2}{*}{29} & BoNT/D substrate & AQVDEVVDIMRVNVDKVLERDQKLSELDDRADALQAGAS & 4312.16 \\
\hline & BoNT/D NT product & AQVDEVVDIMRVNVDKVLERDQK & 2698.4 \\
\hline
\end{tabular}

${ }^{\star}$ Isotopically labelled on $\mathrm{C}$ and $\mathrm{N}$ in 7 positions.

$\dagger$ Attached to Lys $\varepsilon-\mathrm{NH}-\mathrm{CO}-\mathrm{CH}_{2}-\mathrm{CH}_{2}-\left(\mathrm{CF}_{2}\right)_{5}-\mathrm{CF}_{3}$.

$\ddagger$ Attached to Lys $\varepsilon-\mathrm{NH}-\mathrm{CO}-\mathrm{CH}_{2}-\mathrm{O}-\mathrm{CH}_{2}-\mathrm{CO}-\mathrm{CH}_{2}-\mathrm{NH}-\mathrm{CH}_{2}-\mathrm{CH}_{2}-\left(\mathrm{O}-\mathrm{CH}_{2}-\mathrm{CH}_{2}\right)_{6}-\mathrm{O}-\mathrm{CH}_{2}-\mathrm{CH}_{2}-\mathrm{NH}_{2}$.

euthanized wild birds (one jackdaw and one mallard) and one cow at autopsy, all with clinical signs of botulism. The study included sera from six poultry outbreaks, liver or serum samples from three wild birds, liver from one cow and one feed sample. The samples are listed in Table 2.

The toxin was eluted from $20 \mathrm{~g}$ of liver and feed samples using $0.01 \mathrm{M}$ phosphate buffer (sample:buffer 1:1, w/w). The sample was homogenized with a scalpel in the phosphate buffer. Thereafter the sample was centrifuged with cooling $\left(+5^{\circ} \mathrm{C}\right)$ at 4000 r.p.m. for $1 \mathrm{~h}$. The supernatant (the extract of the sample) was used for injection. Sera were used without pretreatment. All samples were mixed with 0.1 M PBST (sample:PBST 9:1, v/v) prior to toxin extraction for Endopep-MS. Positive control samples were prepared by spiking reference toxin complexes (BoNT/A, /B, /C1, /D, /E and /F) into normal chicken serum and liver. Negative controls consisting of pure PBST, serum and chicken liver were also included in the analysis.
Mouse bioassay. Pooled sera, liver extract from affected animals and extract from the feed were tested for C. botulinum toxins /A to /E by the mouse bioassay performed according to the Nordic Committee on Food Analysis (NMKL, 1991). Mice weighing approximately $20 \mathrm{~g}$ were used. For each test, two mice were injected intraperitoneally (i.p.) with $0.5 \mathrm{ml}$ of serum or liver or feed extract and observed for up to 4 days for clinical signs of botulism. Mice were euthanized if signs of botulism developed. Controls consisting of $0.5 \mathrm{ml}$ boiled (heated to $100{ }^{\circ} \mathrm{C}$ for $10 \mathrm{~min}$ ) serum or extract (from liver or feed) were each injected into two mice to determine whether the toxic agent was thermolabile.

The sera or extract were diluted $1: 5,1: 10$ and $1: 100($ in $0.9 \% \mathrm{NaCl})$ to determine the lowest lethal dilution of the toxin, and $0.5 \mathrm{ml}$ of each dilution was injected i.p. into two mice each.

Identification was done by neutralization with specific antibodies to BoNT/A, /B, /C1, /D and /E. The mixture with $0.1 \mathrm{ml}$ antitoxin

Table 2. Sample information and detection of BoNT by mouse bioassay and Endopep-MS

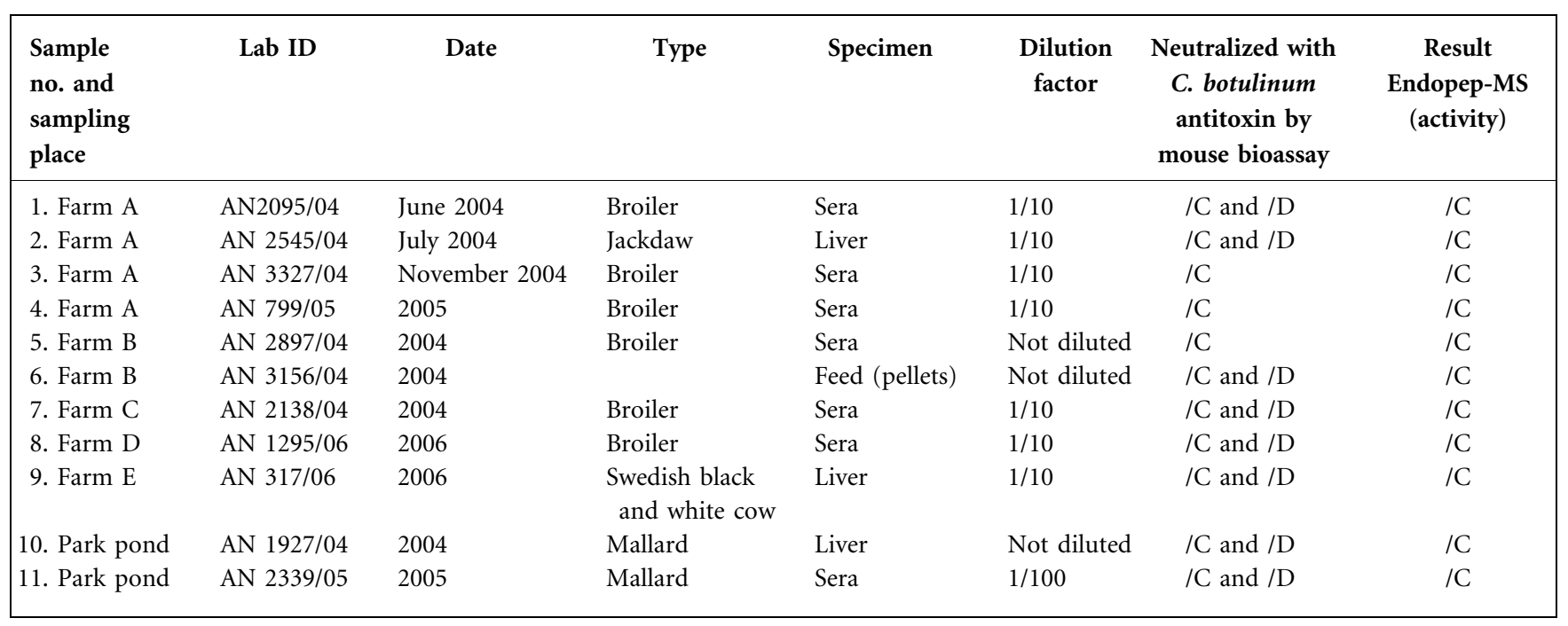


solution and $1 \mathrm{ml}$ toxic serum or extract of the lowest lethal dilution was allowed to stand at room temperature for $1 \mathrm{~h}$ before a $0.5 \mathrm{ml}$ injection i.p. Two mice were used for each mixture. Simultaneously, sera or extract without antitoxin were injected into two other mice. Mice injected with a mixture of the homologous antitoxin and the toxic material survived and mice injected with mixtures of heterologous antitoxins and the toxic material developed clinical signs of botulism. The testing was approved by the Swedish Ethical Committee on Animal Experiments.

IgG binding to Protein G beads for the Endopep-MS method. The specific IgGs were immobilized and cross-linked to the Dynabeads Protein G according to the supplier's protocol and as described before (Kalb et al., 2006). Briefly, 50-200 $\mu \mathrm{g}$ of IgG (antiBoNT/A, /B, /E and /F separately and anti-/C1, /C1D, /DC1 and /D in a mixture) was diluted into $500 \mu \mathrm{l}$ PBS for every $100 \mu \mathrm{l}$ of Dynabeads Protein G. Cross-linked IgG-coated Dynabeads were stored in PBST at $4{ }^{\circ} \mathrm{C}$ for up to 4 weeks.

BoNT extraction and Endopep-MS. Samples were first incubated for $1 \mathrm{~h}$ with $20 \mu \mathrm{l}$ of anti-BoNT/C1, /CD, /D, /DC antibody-coated magnetic beads. The samples were then incubated separately with anti-BoNT/A, /B, /E and /F antibody-coated magnetic beads. After mixing for $1 \mathrm{~h}$ with constant agitation at room temperature, the respective beads were washed twice in $1 \mathrm{ml}$ each of PBST and then washed once in $100 \mu \mathrm{l}$ water. The Endopep-MS reaction was performed as previously described (Barr et al., 2005; Boyer et al., 2005; Kalb et al., 2006) with the modifications described below. Beads were reconstituted in a $20 \mu \mathrm{l}$ solution containing $0.02 \mathrm{M}$ HEPES ( $\mathrm{pH}$ 7.3), $10 \mathrm{mM}$ dithiothreitol, $0.2 \mathrm{mM} \mathrm{ZnCl}_{2}, 1 \mathrm{mg} \mathrm{BSA} \mathrm{ml}^{-1}$ and $50 \mathrm{pmol}$ of the substrate peptide $\mu \mathrm{l}^{-1}$ [separate reactions for BoNT/A, $/ \mathrm{B}, / \mathrm{E}$ and /F substrates respectively, and a mixed reaction with three peptides (\#4, \#128 and \#171) for /C1 and one peptide (\#29) for /D]. The target peptide sequences and the cleavage products for BoNT/A, /B, /E and /F are the same as those described by Boyer et al. (2005). Table 1 lists the peptide sequences used to detect and differentiate BoNT/C1 and /D serotypes along with the specific cleavage products, including stable-isotope peptides used as internal standards and their masses. A mixture of three substrate peptides was used in the reaction for testing BoNT/C1 (\#4 and \#171 derived from the protein SNAP25 and \#128 derived from Syntaxin) and one peptide was used for BoNT/D (\#29 derived from VAMP-2). All samples then were incubated at $37^{\circ} \mathrm{C}$ for $4-16 \mathrm{~h}$ with no agitation.

MALDI-TOF MS detection. From each reaction supernatant, $2.0 \mu \mathrm{l}$ was added to $18 \mu \mathrm{l}$ MALDI matrix solution consisting of $\alpha$-cyano- 4 hydroxycinnamic acid (CHCA) at $5 \mathrm{mg} \mathrm{ml}^{-1}$ in $50 \%$ acetonitrile, $0.1 \%$ trifluoracetic acid and $1 \mathrm{mM}$ ammonium phosphate. Aliquots of $0.8 \mu \mathrm{l}$ of this mixture were pipetted onto each spot of a 384-spot MALDI plate (AB Sciex). Mass spectra of each spot were obtained by scanning from 1000 to $4800 \mathrm{~m} / z$ in MS-positive ion reflectron mode on an Applied Biosystems 4800 Proteomics Analyser (AB Sciex). The instrument uses an nd:YAG laser at $337 \mathrm{~nm}$ and $200 \mathrm{mHz}$ repetition rate. Pulsed ion extraction was set to zero. Acceleration voltage was set to $20 \mathrm{kV}$, and each spectrum was an average of 2400 laser shots.

\section{RESULTS}

The results from the mouse bioassay of the 11 samples tested are given in Table 2. Eight samples were found to be neutralized by both BoNT/C1 and /D antitoxins, whereas three samples were neutralized only by BoNT/C1 antitoxin, although there was a delayed toxic reaction for samples treated with the $/ \mathrm{D}$ antitoxin, i.e. onset of symptoms after about 2 days compared to a few hours for the other subtypes. The dilution factor is an indirect measure of the concentration of the active toxin in the sample, as it denotes the volume factor by which the samples could be diluted and still give a positive result (for the dilution procedure, see Methods). Most of the samples had a maximal lethal dilution of $1 / 10$. However, samples 5 and 6 from farm $B$ as well as sample 10 from a park pond seemed to be less concentrated as they only showed toxicity in their undiluted form. Sample 11 appeared to be the most toxic, as a $1 / 100$ dilution could still give rise to botulism in the mice.

The clinical samples together with positive and negative controls were also analysed using the Endopep-MS method. All the clinical samples (Table 2) gave positive results for BoNT/C1 activity, based on the detection of the peptide \#4 cleavage products at $\mathrm{m} / z 1059.5$ and $\mathrm{m} / z$ 1870.9, the peptide \#128 cleavage products at $\mathrm{m} / \mathrm{z} 1281.7$ and $\mathrm{m} / \mathrm{z}$ 1836.9, and the peptide \#171 cleavage products at $\mathrm{m} / \mathrm{z}$ 1299.8 and $\mathrm{m} / z$ 1870.9. The latter one is isobaric with one of the fragments of peptide \#4. The mass spectrum of sample 8 is shown as an example in Fig. 1(a). There was no evidence for activity of any of the other toxin serotypes above the respective limits of detection (results not shown). All the positive controls consisting of avian serum and liver tissue spiked with BoNT/A to /F turned out to be positive in terms of the presence of the anticipated peptide cleavage products (data not shown). The result of a typical positive control sample containing BoNT/C1 at $5 \mathrm{LD}_{50} / 500 \mu \mathrm{l}$ in serum is shown in Fig. 1(b). The matrix-based blanks containing blank serum and chicken liver did not show any specific cleavage of the substrate peptides; a typical mass spectrum from a blank serum sample is shown in Fig. 1(c). Mass spectra from all the samples described in Table 2 are available as supplementary figures with the online version of this paper.

The jackdaw (sample 2, Table 2) was found dead on farm A, which had ongoing botulism among its poultry. It is thus apparent that both wild and domestic birds can be affected during an outbreak. Even though farm A is geographically separated from farms B and C, it cannot be ruled out that the outbreaks emanated from a common source, as the cases occurred within a quite narrow time-frame. The cow (sample 9) had been fed with silage. However, it was never proven that this was the source of the toxin.

\section{DISCUSSION}

There have been many outbreaks of botulism among wild birds and poultry during recent years (Lindström et al., 2004; Shin et al., 2010). The method widely used for detection has been the mouse bioassay. Although this method is sensitive and detects active toxin, it suffers from major disadvantages such as a time scale of at least 4 days, the need for relatively large sample volumes, and a large consumption of laboratory animals (Cai et al., 2007). Thus there has been a great need for a faster, equally sensitive method which is not based on animal use. 

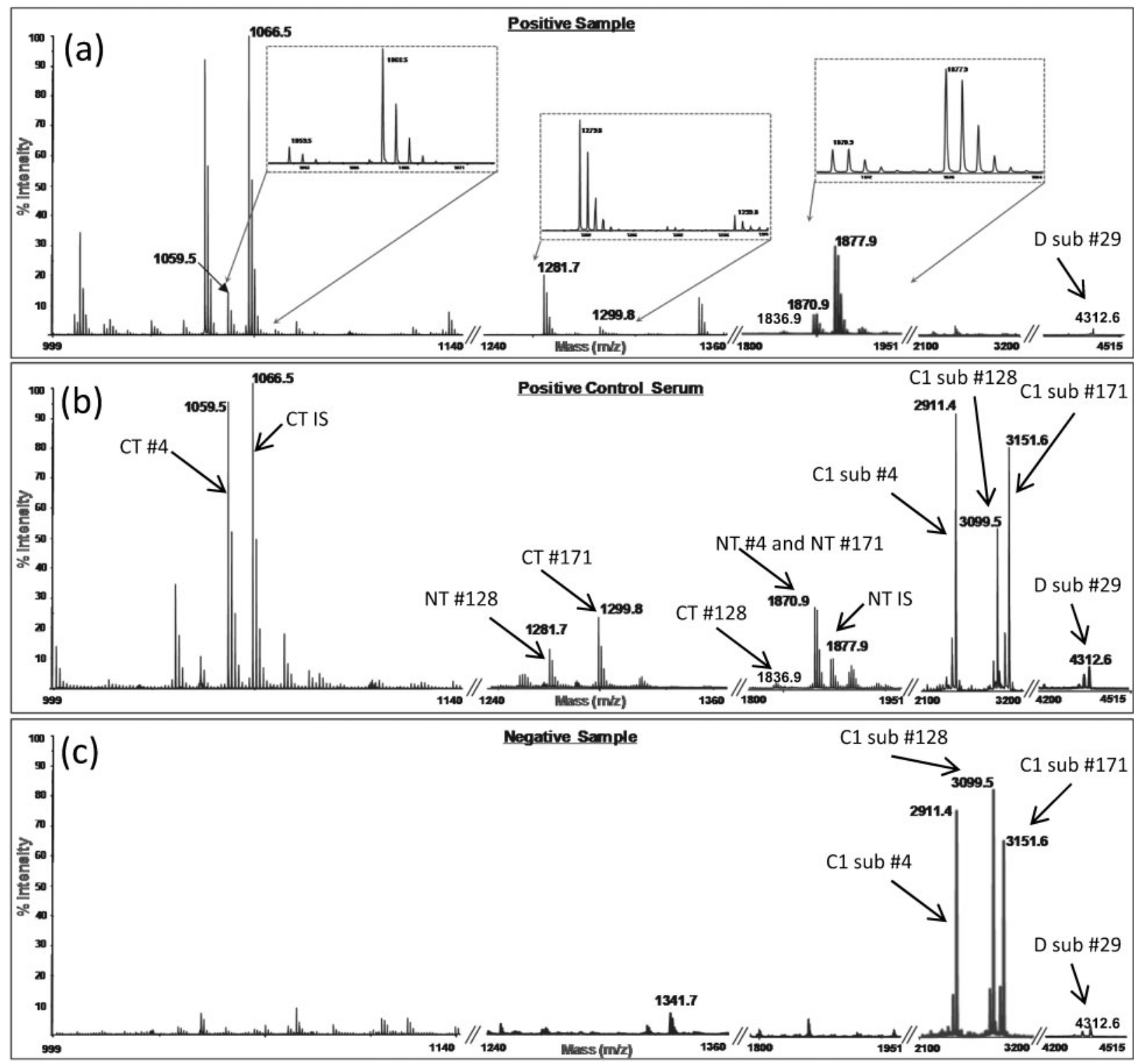

Fig. 1. BoNT/C1 proteolytic activity detected by MALDI-TOF MS: representative Endopep-MS spectra in avian sera after extraction with antibody-coated magnetic beads. Peptide-based antibodies were prepared against BoNT/C1, /C1D, /D and /DC1. Three substrate peptides for BoNT/C1 ( $/ \mathrm{z}$ 2911.4, 3099.5 and 3151.6), and one substrate peptide for BoNT/D $(\mathrm{m} / \mathrm{z}$ 4312.6), were included in the reactions. Typical spectra depict the expected peptide products and respective isotopelabelled standards (ISTD) in the positive reactions with a typical positive serum sample (a), and a positive control consisting of serum spiked with BoNT/C1 at 5 mouse $\mathrm{LD}_{50} / 500 \mu \mathrm{l}$ (b). BoNT/C1 hydrolyses the synthetic peptide substrate \#4 $(\mathrm{m} / \mathrm{z}$ 2911.4 ) to yield peptide products at $\mathrm{m} / \mathrm{z} 1870.9$ (NT) and 1059.5 (CT). ISTD peaks are at $\mathrm{m} / \mathrm{z} 1877.9$ and 1066.5 respectively. The substrate peptide \#128 yielded products at $\mathrm{m} / \mathrm{z} 1281.7$ (NT) and 1836.9 (CT), whereas substrate peptide \#171 yielded products at $\mathrm{m} / \mathrm{z} 1870.9$ (NT - isobaric with the NT product of substrate \#4) and 1299.8 (CT). No cleavage product was detected for BoNT/D. In (c) only intact substrate peptides are detected in the absence of toxin.

In this study, the Endopep-MS method has for the first time been applied to detect BoNT activity in selected clinical samples of animal origin that previously tested positive with the mouse bioassay. This is the beginning of cross-validation studies between the two methods. The previously tested substrate peptide (\#4, derived from
SNAP-25, Table 1; Boyer et al., 2005; Moura et al., 2011) for detection of BoNT/C1 in buffer solutions sometimes gave unspecific cleavage, thus creating false positives. In order to overcome this problem, two additional substrates that proved to be more stable were included in this study (\#128 derived from syntaxin and \#171 derived from 
SNAP-25, Table 1). However, the sensitivity for BoNT/C1 was slightly lower using the latter two peptides separately, and a mixture of all three substrates was used to improve the consistency of the data.

It is interesting to note that all the samples reacted as being BoNT/C1 in the Endopep-MS method, whereas the majority of them had been neutralized by antibodies against both BoNT/C1 and /D in the mouse bioassay. A probable explanation for this phenomenon is the occurrence of the above-mentioned BoNT/C1D mosaic, where the sequence of the light protein chain of the toxin is similar to that of BoNT/C1 while the heavy chain has sequences similar to both /C1 and /D (Takeda et al., 2005). As the enzymically active site resides within the light chain, the BoNT/C1D mosaic is expected to cleave the substrate peptide identically to BoNT/C1 and thus gives a pure /C1 response in the Endopep-MS assay. Using specific antibodies to BoNT/C1 and /D heavy chains in combination with the specific enzymic activity of these two toxins should permit the differentiation of BoNT/C1 from the /C1D mosaic. We are currently preparing antibodies that should aid the differentiation of BoNT/C1 from the /C1D mosaic along with BoNT/D from the /DC1 mosaic. In a previous study, intestinal contents from broilers from the same farm as the ones giving rise to the serum samples 1 and 8 were also analysed by PCR and concomitant sequencing of the amplicons (Lindberg et al., 2010). The results were consistent with the presence of the BoNT/C1D mosaic gene.

There are discrepancies in the qualitative mouse test results between samples from the same farm (A and B) taken at different time points (Table 2). For farm A, samples 1 and 2 gave $/ \mathrm{C} 1$ and $/ \mathrm{D}$ in the mouse bioassay, whereas samples 3 and 4 gave only /C1 as the result. Furthermore, for farm $\mathrm{B}$, sample 6 gave the result /C1 and /D and sample 5 gave only /C1. However, all the samples that qualitatively had pure / $\mathrm{C} 1$ based on mouse test results in this study also gave a delayed toxic reaction after neutralization with antitoxin $/ D$, i.e. onset of clinical signs of botulism after 2 days compared to the usual few hours. This observation suggests that antitoxin /D had some degree of affinity to the toxin serotype present in these samples $(3,4$ and 5$)$. Thus, the seeming paradox of qualitatively different serotypes in samples from the same outbreak may be explained by a quantitative factor such as the toxin level in relation to the neutralizing efficiency of the anti-/D antibodies. The corresponding phenomenon of a partial effect of antitoxin /C on the BoNT/DC1 mosaic was described by others (Nakamura et al., 2010).

In conclusion, this study is the initial step of a crossvalidation between the Endopep-MS method and the mouse bioassay and has, to the best of our knowledge, for the first time demonstrated that an enzymic-mass spectrometric technique can detect BoNT/C1 activity in clinical samples of animal origin. The use of Endopep-MS has given evidence that the enzymically active sites and thereby the light protein chains of all the samples tested were of / $\mathrm{C} 1$ serotype, whereas the mouse bioassay has given important information on the influence of BoNT/D structures, probably in the heavy chain as previously described for the BoNT/C1D mosaic (Takeda et al., 2005). Thus, in this study the Endopep-MS alone would not have been able to differentiate between BoNT/C1 and /C1D, whereas the mouse bioassay has been unable to tell BoNT/ $\mathrm{C} 1 \mathrm{D}$ and /DC1 apart. However, further development of the antibody capture technique in the Endopep-MS method may increase the degree of selectivity for this technique against different toxin mosaics. Thus, Endopep-MS is anticipated to be an attractive alternative to the mouse bioassay.

\section{ACKNOWLEDGEMENTS}

The Swedish Animal Welfare Agency is gratefully acknowledged for financial support of this project. This sponsor had no influence on the study design, collection or interpretation of data or writing of the manuscript. References to specific commercial products, processes, services, manufacturers or companies do not constitute an endorsement or a recommendation by the US Government or by the Centers for Disease Control and Prevention (CDC). The findings and conclusions in this report are those of the authors and do not necessarily represent the views of CDC.

\section{REFERENCES}

Barr, J. R., Moura, H., Boyer, A. E., Woolfitt, A. R., Kalb, S. R., Pavlopoulos, A., McWilliams, L. G., Schmidt, J. G., Martinez, R. A. \& Ashley, D. L. (2005). Botulinum neurotoxin detection and differentiation by mass spectrometry. Emerg Infect Dis 11, 1578-1583.

Blomqvist, G., Skarin, H., Lindberg, A., Båverud, V. \& Engström, B. (2009). Surveillance for Clostridium botulinum type $C$ or $C / D$ in Swedish broilers. In The 16th World Vet Poultry Congress, p. 415. Marrakesh, Morocco.

Boyer, A. E., Moura, H., Woolfitt, A. R., Kalb, S. R., McWilliams, L. G., Pavlopoulos, A., Schmidt, J. G., Ashley, D. L. \& Barr, J. R. (2005). From the mouse to the mass spectrometer: detection and differentiation of the endoproteinase activities of botulinum neurotoxins $A-G$ by mass spectrometry. Anal Chem 77, 3916-3924.

Cai, S., Singh, B. R. \& Sharma, S. (2007). Botulism diagnostics: from clinical symptoms to in vitro assays. Crit Rev Microbiol 33, 109-125.

Evans, H. R., Holloway, D. E., Sutton, J. M., Ayriss, J., Shone, C. C. \& Acharya, K. R. (2004). C3 exoenzyme from Clostridium botulinum: structure of a tetragonal crystal form and a reassessment of NADinduced flexure. Acta Crystallogr D Biol Crystallogr 60, 1502-1505.

Evans, E. R., Skipper, P. J. A. \& Shone, C. C. (2009). An assay for botulinum toxin types $\mathrm{A}, \mathrm{B}$ and $\mathrm{F}$ that requires both functional binding and catalytic activities within the neurotoxin. J Appl Microbiol 107, 1384-1391.

Ferracci, G., Marconi, S., Mazuet, C., Jover, E., Blanchard, M. P., Seagar, M., Popoff, M. \& Lévêque, C. (2011). A label-free biosensor assay for botulinum neurotoxin B in food and human serum. Anal Biochem 410, 281-288.

Fujinaga, Y., Inoue, K., Watanabe, S., Yokota, K., Hirai, Y., Nagamachi, E. \& Oguma, K. (1997). The haemagglutinin of Clostridium botulinum type $\mathrm{C}$ progenitor toxin plays an essential role in binding of toxin to the epithelial cells of guinea pig small intestine, 
leading to the efficient absorption of the toxin. Microbiology 143, 3841-3847.

Hallis, B., James, B. A. \& Shone, C. C. (1996). Development of novel assays for botulinum type A and B neurotoxins based on their endopeptidase activities. J Clin Microbiol 34, 1934-1938.

Johnson, E. A. \& Montecucco, C. (2008). Botulism. In Handbook of Clinical Neurology, 2008/07/18 edn, vol. 91, pp. 333-368. Edited by P. J. Vinken \& G. W. Bruyn. New York/Amsterdam: Elsevier.

Jones, R. G., Liu, Y. \& Sesardic, D. (2009). New highly specific botulinum type $\mathrm{C} 1$ endopeptidase immunoassays utilising SNAP25 or Syntaxin substrates. J Immunol Methods 343, 21-27.

Kalb, S. R., Goodnough, M. C., Malizio, C. J., Pirkle, J. L. \& Barr, J. R. (2005). Detection of botulinum neurotoxin A in a spiked milk sample with subtype identification through toxin proteomics. Anal Chem 77, 6140-6146.

Kalb, S. R., Moura, H., Boyer, A. E., McWilliams, L. G., Pirkle, J. L. \& Barr, J. R. (2006). The use of Endopep-MS for the detection of botulinum toxins A, B, E, and F in serum and stool samples. Anal Biochem 351, 84-92.

Kautter, D. A. \& Solomon, H. M. (1977). Collaborative study of a method for the detection of Clostridium botulinum and its toxins in foods. J Assoc Off Anal Chem 60, 541-545.

Lindberg, A., Skarin, H., Knutsson, R., Blomqvist, G. \& Båverud, V. (2010). Real-time PCR for Clostridium botulinum type C neurotoxin (BoNTC) gene, also covering a chimeric C/D sequence - application on outbreaks of botulism in poultry. Vet Microbiol 146, 118-123.

Lindström, M., Nevas, M., Kurki, J., Sauna-aho, R., Latvala-Kiesilä, A., Pölönen, I. \& Korkeala, H. (2004). Type C botulism due to toxic feed affecting 52,000 farmed foxes and minks in Finland. J Clin Microbiol 42, 4718-4725.

Maksymowych, A. B., Reinhard, M., Malizio, C. J., Goodnough, M. C., Johnson, E. A. \& Simpson, L. L. (1999). Pure botulinum neurotoxin is absorbed from the stomach and small intestine and produces peripheral neuromuscular blockade. Infect Immun 67, 4708-4712.

Moura, H., Kalb, S. R., Woolfitt, A. R., Gallegos-Candela, M., Smith, T. J., Smith, L. A., Marks, J. D., Lou, J., Garcia-Rodriguez, C. \& other authors (2008). Revisiting botulinum neurotoxins C and D using Endopep-MS and proteomics. In 45th Annual Interagency Botulism Research Coordinating Committee (IBRCC) Meeting. Philadelphia, PA, USA.
Moura, H., Terilli, R. R., Woolfitt, A. R., Gallegos-Candela, M., McWilliams, L. G., Solano, M. I., Pirkle, J. L. \& Barr, J. R. (2011). Studies on botulinum neurotoxins type /C1 and mosaic/DC using Endopep-MS and proteomics. FEMS Immunol Med Microbiol 61, 288-300.

Nakamura, K., Kohda, T., Umeda, K., Yamamoto, H., Mukamoto, M. \& Kozaki, S. (2010). Characterization of the D/C mosaic neurotoxin produced by Clostridium botulinum associated with bovine botulism in Japan. Vet Microbiol 140, 147-154.

Neimanis, A., Gavier-Widén, D., Leighton, F., Bollinger, T., Rocke, T. \& Mörner, T. (2007). An outbreak of type C botulism in herring gulls (Larus argentatus) in southeastern Sweden. J Wildl Dis 43, 327-336.

NMKL (1991). Botulinum Toxin, Detection in Foods, Blood and Other Test Materials, 2nd edn, vol. 79. Oslo: Nordic Committee on Food Analysis.

Quinn, P. J., Carter, M. E., Markey, B. K. \& Carter, G. R. (1994). Clostridium species. In Clinical Veterinary Microbiology, pp. 196-200. London: Wolfe Publishing.

Schiavo, G., Matteoli, M. \& Montecucco, C. (2000). Neurotoxins affecting neuroexocytosis. Physiol Rev 80, 717-766.

Shin, N. R., Byun, S. H., Chun, J. H., Shin, J. H., Kim, Y. J., Kim, J. H., Rhie, G. E., Chung, H. M., Mo, I. P. \& Yoo, C. K. (2010). An outbreak of type C botulism in waterbirds: Incheon, Korea. J Wildl Dis 46, 912-917.

Skarin, H., Lindberg, A., Blomqvist, G., Aspán, A. \& Båverud, V. (2010). Molecular characterization and comparison of Clostridium botulinum type C avian strains. Avian Pathol 39, 511-518.

Takeda, M., Tsukamoto, K., Kohda, T., Matsui, M., Mukamoto, M. \& Kozaki, S. (2005). Characterization of the neurotoxin produced by isolates associated with avian botulism. Avian Dis 49, 376-381.

Wictome, M. \& Shone, C. C. (1998). Botulinum neurotoxins: mode of action and detection. Symp Ser Soc Appl Microbiol 27, 87S-97S.

Wictome, M., Newton, K. A., Jameson, K., Dunnigan, P., Clarke, S., Gaze, J., Tauk, A., Foster, K. A. \& Shone, C. C. (1999a). Development of in vitro assays for the detection of botulinum toxins in foods. FEMS Immunol Med Microbiol 24, 319-323.

Wictome, M., Newton, K., Jameson, K., Hallis, B., Dunnigan, P., Mackay, E., Clarke, S., Taylor, R., Gaze, J. \& other authors (1999b). Development of an in vitro bioassay for Clostridium botulinum type B neurotoxin in foods that is more sensitive than the mouse bioassay. Appl Environ Microbiol 65, 3787-3792. 